\title{
A remnant choledochal cyst after choledochal cyst excision treated with a lumen-apposing metal stent: a case report
}

\author{
Bo Kyung Kim, Jung Won Chun, Sang Hyub Lee, Ji Kon Ryu, Yong-Tae Kim, Woo Hyun Paik \\ Department of Internal Medicine and Liver Research Institute, Seoul National University Hospital, Seoul National University College of Medicine, Seoul, Korea
}

\begin{abstract}
A lumen-apposing metal stent (LAMS) is a saddle-shaped stent with large flanges at both ends, thereby preventing stent migration and helping with approximation of the adjacent structures. We report the case of a 25 -year-old female with remnant choledochal cyst which was successfully treated with LAMS after initial treatment failure with a plastic stent. Although complete excision of the cyst is the definite treatment of choledochal cysts, endoscopic ultrasonography-guided cystoduodenostomy can be considered in cases wherein surgery is not feasible and dysplasia is not present. LAMS may be preferred to plastic stents for effective resolution of remnant choledochal cyst and prevention of ascending infection.
\end{abstract}

Keywords: Choledochal cyst; Endosonography; Self-expandable metallic stents

\section{INTRODUCTION}

Choledochal cysts are rare anomalies of the biliary system and are classified into 5 types based on their location and shape. ${ }^{1}$ They are associated with an increased risk of malignancy, especially cholangiocarcinoma and gall bladder cancer, which are more common in type I and IV cysts. ${ }^{2,3}$ Roux-en-Y hepaticojejunostomy is the standard treatment in type I and IV cysts due to the increased risk of malignancy.

A lumen-apposing metal stent (LAMS) is a saddle-shaped stent with flanged ends developed for endoscopic intervention. ${ }^{5}$ It was originally designed for the drainage of pancreatic fluid

Received: September 9, 2019

Revised: October 25, 2019

Accepted: November 9, 2019

Correspondence: Woo Hyun Paik

Department of Internal Medicine and Liver Research Institute, Seoul National University Hospital, Seoul National University College of Medicine, 101 Daehak-ro, Jongno-gu, Seoul 03080, Korea

E-mail:whpaik@snuh.org

(a) This is an Open Access article distributed under the terms of the Creative Commons Attribution Non-Commercial License (http://creativecommons.org/licenses/by-nc/4.0/) which permits unrestricted non-commercial use, distribution, and reproduction in any medium, provided the original work is properly cited. collection (PFC) and has shown high clinical (77\%-96\%) and technical $(91 \%-100 \%)$ success rates. ${ }^{5-7}$ The unique shape of LAMS with wide flanges, a large lumen, and short length as well as its lumen-apposing property is expected to enable effective drainage and reduce the risk of migration and peritoneal leakage. Because of this characteristic and the satisfactory success rates in the treatment of PFC, off-label usage for other indications has been proposed and has gained popularity. However, as clinical experiences with LAMS have accumulated, complication such as bleeding and buried LAMS syndrome have emerged.

Herein, we report a case of a remnant choledochal cyst which was successfully treated with LAMS after initial treatment failure with a plastic stent.

\section{CASE REPORT}

A 25-year-old woman presented to the emergency room with right upper quadrant (RUQ) abdominal pain and a palpable mass. The pain had been initially intermittent for several months and was aggravated one week prior. Associated symptoms included nausea and vomiting. 
Her blood pressure was $118 / 75 \mathrm{mmHg}$, heart rate was 88 beats/min, respiratory rate was 16 breaths/min, and body temperature was $37^{\circ} \mathrm{C}$. On physical examination, RUQ tenderness and a large palpable RUQ mass were noted. Laboratory studies revealed the following: white blood cell count $10,100 / \mu \mathrm{L}$, hemoglobin $12.3 \mathrm{~g} / \mathrm{dL}$, platelet count $202 \times 10^{3} / \mu \mathrm{L}$, total bilirubin $0.8 \mathrm{~g} / \mathrm{dL}$, alkaline phosphatase $112 \mathrm{IU} / \mathrm{L}$, aspartate aminotransferase $52 \mathrm{IU} / \mathrm{L}$, alanine aminotransferase $173 \mathrm{IU} / \mathrm{L}$, gamma glutamyltranspeptidase $167 \mathrm{IU} / \mathrm{L}, \mathrm{C}$-reactive protein $0.80 \mathrm{mg} / \mathrm{dL}$, carbohydrate antigen 19-9 $13.5 \mathrm{U} / \mathrm{mL}$, and carcinoembryonic antigen $0.9 \mathrm{ng} / \mathrm{mL}$.

Abdominal computed tomography (CT) and magnetic resonance cholangiopancreatography showed huge cystic dilatation of the common bile duct and multifocal intrahepatic bile duct dilatation, which was suggestive of choledochal cyst, Todani classification type IVa (Fig. 1). There was neither a definite obstructive lesion nor enhancing mural nodule. Anomalous pancreaticobiliary ductal union (APBDU) was not definite. The patient received excision of the choledochal cyst with Roux-en-Y hepaticojejunostomy. On microscopy, no dysplastic epithelium was seen in the excised cyst.

At 7 months post-surgery, abdominal CT revealed a large remnant cyst. As the patient refused reoperation and complained of intermittent RUQ pain and discomfort, endoscopic ultrasonography (EUS)-guided cystoduodenostomy with a $7 \mathrm{Fr}$ $\times 7 \mathrm{~cm}$ double-pigtail plastic stent was performed (Fig. 2).

However, she was admitted 10 days after the procedure with fever, RUQ pain, nausea, and C-reactive protein elevation of $23.38 \mathrm{mg} / \mathrm{dL}$. Her blood pressure was 94/61 $\mathrm{mmHg}$, heart rate was 101 beats/min, respiratory rate was 18 breaths/ min, and body temperature was $38.2^{\circ} \mathrm{C}$. Abdominal CT showed an increase in the size of the cyst with wall thickening and air-fluid level suggestive of cyst infection. Endoscopic sphincterotomy and endoscopic retrograde pancreatic drainage with a $7 \mathrm{Fr} \times 10 \mathrm{~cm}$ single-pigtail plastic stent was done to enhance the natural drainage of the remnant cyst and reduce the reflux of pancreatic juice into the remnant cyst (Fig. 3). There was neither microorganisms nor white blood cells in the EUS-guided cyst aspiration. However, since the remnant cyst still persisted one month later, the patient was readmitted for cystoduodenostomy stent removal and an endoscopic retrograde biliary drainage trial. Bile duct cannulation failed due to anatomical variation by the large remnant choledochal cyst. As the plastic stent was insufficient for effective drainage and seemed to cause duodenocystic reflux, cystoduodenostomy stent revision was performed with LAMS (SPAXUS; Taewoong Medical, Gimpo, Korea; $10 \mathrm{~mm} \times 20 \mathrm{~mm}$ ) which had a larger inner lumen (Fig. 4).

Six months after the procedure, abdominal CT showed a marked decrease in the size of the remnant cyst and LAMS was subsequently removed. Abdominal CT taken 1 year after LAMS removal showed resolution of the remnant cyst (Fig. 5). The patient is currently on routine checkup without any symptoms.
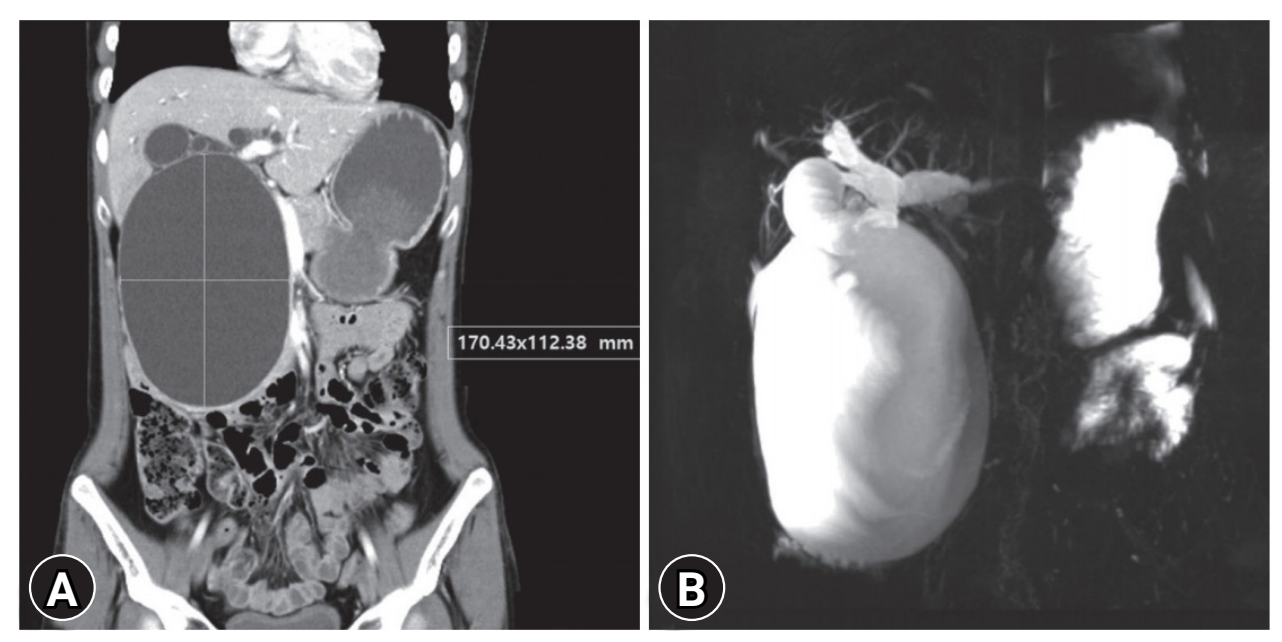

Fig. 1. (A) Abdominal computed tomography and (B) magnetic resonance cholangiopancreatography taken at initial presentation. Huge cystic dilatation of the common bile duct with bilateral intrahepatic duct dilatation and abrupt luminal diameter change in the peripheral duct was observed, suggestive of choledochal cyst, type IVa. 



Fig. 2. (A) Abdominal computed tomography showed the remnant choledochal cyst after choledochal cyst excision. (B, C) Endoscopic ultrasonography-guided cystoduodenostomy at the second portion of the duodenum with a plastic stent was performed.
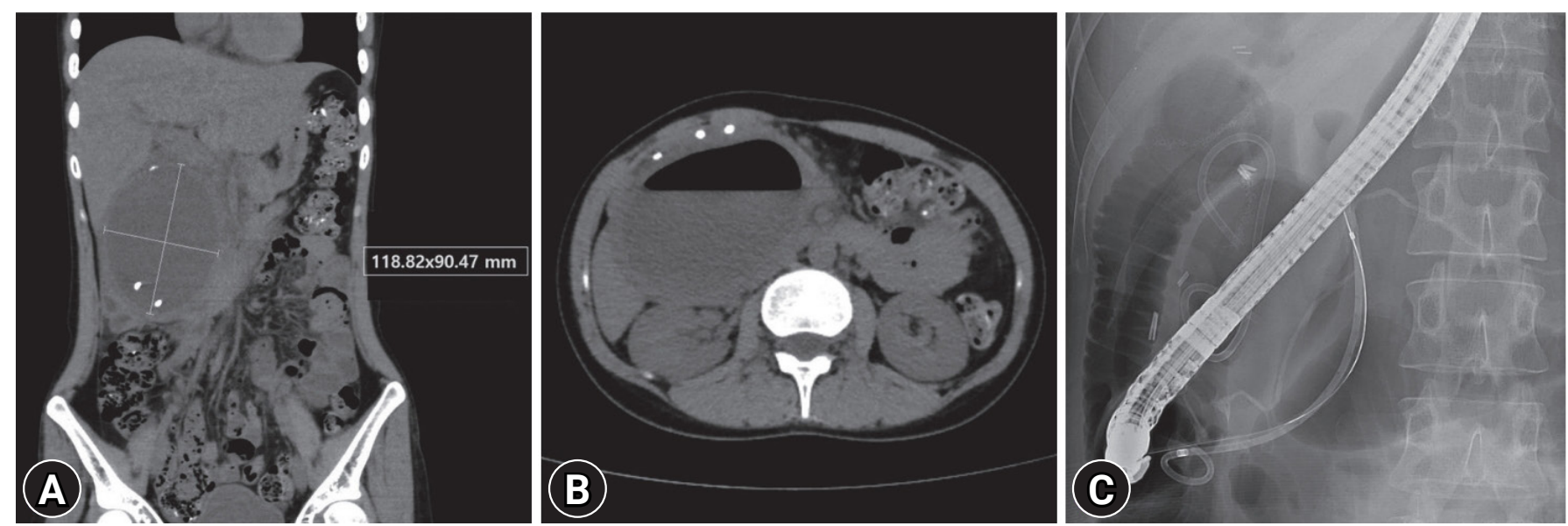

Fig. 3. Abdominal computed tomography showed (A) an increase in the size of the remnant choledochal cyst and (B) wall thickening with air-fluid level suggestive of cyst infection. (C) Endoscopic retrograde cholangiopancreatography showed the distorted pancreatic duct compressed by the remnant choledochal cyst. Endoscopic retrograde pancreatic drainage was done. Bile duct cannulation failed.
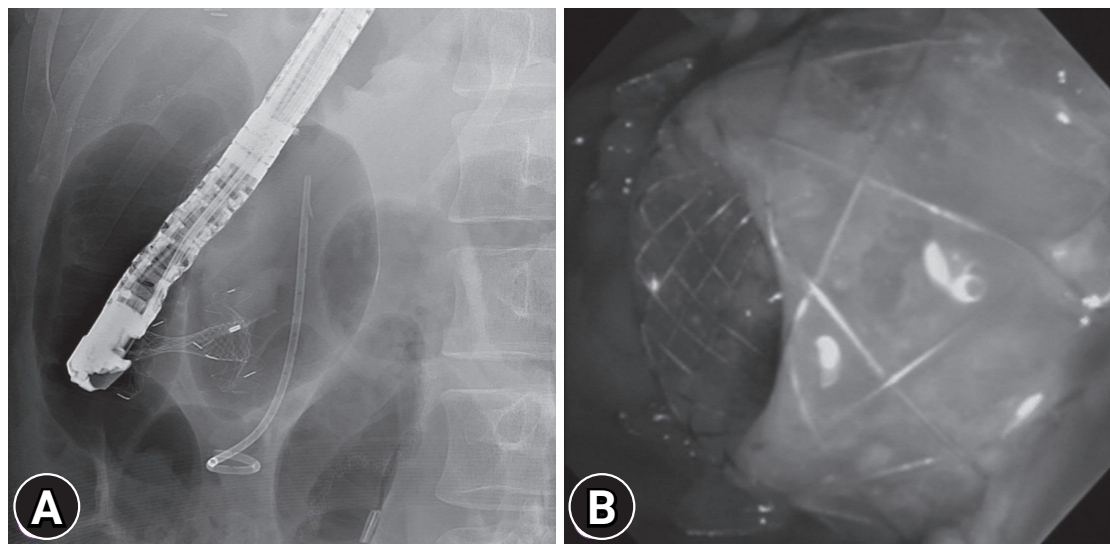

Fig. 4. (A, B) Cystoduodenostomy stent revision was done with a lumen-apposing metal stent. The previously inserted pancreatic stent was also noted. 



Fig. 5. Drainage of the remnant choledochal cyst with lumen-apposing metal stent (LAMS). (A) Abdominal computed tomography taken 6 months after LAMS insertion showed an interval decrease in the size of the infected cyst. LAMS was subsequently removed. (B) Abdominal computed tomography taken 1 year after LAMS removal showed resolution of the remnant cyst.

\section{DISCUSSION}

Complete surgical resection of a choledochal cyst may be difficult depending on the cyst extent and size and recurrent inflammation, which results in the adhesion of adjacent structures. ${ }^{8}$ A remnant cyst after incomplete resection is associated with an increased risk of malignancy and patients with a remnant cyst should receive regular surveillance. ${ }^{9}$ A remnant cyst may also cause complications such as abdominal pain, cholangitis, cholangiolithiasis, and pancreatitis. ${ }^{9,10} \mathrm{Xia}$ et al..$^{10}$ reported 41 cases of remnant intrapancreatic choledochal cyst patients who developed complications and underwent reoperation. Case reports of complicated remnant choledochal cysts showed that internal drainage with stents was effective in the treatment of cyst infections and obstructive symptoms due to the compression of the remnant cyst. ${ }^{11,12}$ EUS-guided drainage of the remnant cyst may be an alternative treatment option if additional surgery for the remnant cyst is not feasible and complications occur. In this case, since the patient refused additional surgery, EUS-guided cystoduodenostomy was done for decompression as the cyst was growing and complications such as abdominal pain and infection occurred.

Two recent reviews of the current uses and outcomes of LAMS showed satisfactory treatment rates for PFC and biliary drainage. Treatment of PFC with LAMS showed clinical and technical success rates of $77 \%-96 \%$ and $91 \%-100 \%$, respec- tively, and adverse event rates of 5\%-15\%. EUS-guided biliary drainage with LAMS revealed high technical and clinical success rates of $86 \%-98 \%$ and $88 \%-100 \%$, respectively, and adverse event rates of $7 \%-36 \%{ }^{5,7}$ Although results are quite promising, large randomized trials comparing LAMS with plastic stents or traditional self-expanding metal stents are rare and safety issues regarding bleeding, buried LAMS syndrome, stent migration, and perforation are non-negligible. ${ }^{13}$ In one randomized trial comparing the efficacy of LAMS and plastic stents for walledoff pancreatic necrosis, no significant difference was observed between groups and higher stent-related adverse events was observed in the LAMS group. ${ }^{14}$

A standard technique for EUS-guided biliary drainage has not been well established. Plastic stents have been widely used in EUS-guided biliary drainage but have had relatively poor patency and high rates of complications such as peritonitis due to bile leakage. ${ }^{15,16}$ Large cysts with a diameter $>15 \mathrm{~cm}$ may be associated with a higher risk of cyst infection after EUS-guided drainage; therefore, multiple-pigtail or larger diameter metal stents are recommended for large cysts to avoid infection. ${ }^{17}$ In this case, a previously placed plastic stent seemed to be ineffective in terms of drainage of the large cyst, and caused cyst infection by presumed duodenocystic reflux with capillarity. For effective drainage of the remnant choledochal cyst, a plastic stent was replaced with LAMS and successful drainage was achieved without major complications. 
Bleeding is considered to be a major complication of LAMS. A possible mechanism of bleeding in patients with PFC who were treated with LAMS is that although PFC resolves and decreases in size, the LAMS remains in place, causing distal flange to irritate and impinge on the adjacent vasculature leading to pseudoaneurysm and major bleeding. ${ }^{18}$ In this case, however, LAMS was placed in the remnant choledochal cyst, which is an isolated space that does not contain complex vasculature. It is reasonable to assume the bleeding risk to be low due to this anatomical characteristic. Considering the advantage and limitations of LAMS, this case showed the usefulness of LAMS in the treatment of a remnant choledochal cyst without dysplasia and APBDU, achieving effective drainage without any major adverse events. LAMS may be superior to plastic stents in terms of the effective resolution of remnant choledochal cysts and prevention of ascending infection.

\section{Conflicts of Interest}

The authors have no potential conflicts of interest.

\section{Funding}

None.

\section{Acknowledgments}

The patient provided informed consent and agreed to publication of the images.

\section{Author Contributions}

Conceptualization: WHP; Data curation: WHP, BKK, JWC; Writing-original draft: WHP, BKK, JWC; Writing-review \& editing: all authors.

\section{ORCID}

Bo Kyung Kim Jung Won Chun Sang Hyub Lee Ji Kon Ryu Yong-Tae Kim Woo Hyun Paik

https://orcid.org/0000-0002-9143-9654 https://orcid.org/0000-0003-1964-7501 https://orcid.org/0000-0003-2174-9726 https://orcid.org/0000-0001-8798-0491 https://orcid.org/0000-0002-4842-6874 https://orcid.org/0000-0001-8708-3280

\section{REFERENCES}

1. Todani T, Watanabe Y, Toki A, et al. Classification of congenital biliary cystic disease: special reference to type Ic and IVA cysts with primary ductal stricture. J Hepatobiliary Pancreat Surg 2003;10:340344.

2. Søreide K, Søreide JA. Bile duct cyst as precursor to biliary tract cancer. Ann Surg Oncol 2007;14:1200-1211.

3. Lee SE, Jang JY, Lee YJ, et al. Choledochal cyst and associated malignant tumors in adults: a multicenter survey in South Korea. Arch Surg 2011;146:1178-1184.

4. Todani T, Tabuchi K, Watanabe $\mathrm{Y}$, et al. Carcinoma arising in the wall of congenital bile duct cysts. Cancer 1979;44:1134-1141.

5. Mussetto A, Fugazza A, Fuccio L, et al. Current uses and outcomes of lumen-apposing metal stents. Ann Gastroenterol 2018;31:535-540.

6. Hammad T, Khan MA, Alastal Y, et al. Efficacy and safety of lumen-apposing metal stents in management of pancreatic fluid collections: are they better than plastic stents? A systematic review and meta-analysis. Dig Dis Sci 2018;63:289-301.

7. Bank JS, Adler DG. Lumen apposing metal stents: a review of current uses and outcomes. Gastrointestinal Intervention 2017;6:9-14.

8. Singham J, Schaeffer D, Yoshida E, et al. Choledochal cysts: analysis of disease pattern and optimal treatment in adult and paediatric patients. HPB (Oxford) 2007;9:383-387.

9. Singham J, Yoshida EM, Scudamore CH. Choledochal cysts. Part 3 of 3: management. Can J Surg 2010;53:51-56.

10. Xia HT, Yang T, Liang B, et al. Treatment and outcomes of adults with remnant intrapancreatic choledochal cysts. Surgery 2016;159:418425.

11. Tan MY, Madhavan KK. An endoscopic approach for drainage of a remnant intra-pancreatic choledochal cyst-a rare complication following choledochal cyst excision causing gastric outlet obstruction. HPB (Oxford) 2018;20(Suppl 2):S751.

12. Yırgın H, Öter V, Aziret M, et al. Remnant choledochal cyst; report of a case. CausaPedia 2017;6:170-175.

13. DeSimone ML, Asombang AW, Berzin TM. Lumen apposing metal stents for pancreatic fluid collections: recognition and management of complications. World J Gastrointest Endosc 2017;9:456-463.

14. Bang JY, Navaneethan U, Hasan MK, et al. Non-superiority of lumen-apposing metal stents over plastic stents for drainage of walledoff necrosis in a randomised trial. Gut 2019;68:1200-1209.

15. Wang K, Zhu J, Xing L, et al. Assessment of efficacy and safety of EUS-guided biliary drainage: a systematic review. Gastrointest Endosc 2016;83:1218-1227.

16. Khashab MA, Messallam AA, Penas I, et al. International multicenter comparative trial of transluminal EUS-guided biliary drainage via hepatogastrostomy vs. choledochoduodenostomy approaches. Endosc Int Open 2016;4:E175-E181. 
17. Guo J, Feng L, Sun S, et al. Risk factors for infection after endoscopic ultrasonography-guided drainage of specific types of pancreatic and peripancreatic fluid collections (with video). Surg Endosc 2016;30:3114-3120.
18. Brimhall B, Han S, Tatman PD, et al. Increased incidence of pseudoaneurysm bleeding with lumen-apposing metal stents compared to double-pigtail plastic stents in patients with peripancreatic fluid collections. Clin Gastroenterol Hepatol 2018;16:1521-1528. 